\title{
Dilemmas for Zanzibar: Energy, Economy and Environment
}

\author{
Sahim Abdalla Juma, PhD. Public Administration, \\ University of Science and Technology of China, School of Public Affairs \\ No.96, JinZhai Road Baohe District, Hefei, Anhui, 230026, P.R.China.
}

\begin{abstract}
This study is presenting a Policy analysis of the relationship between energy, economy, and environment in Zanzibar, Tanzania. The Zanzibar government are in a dilemma to balance between economy, energy system and environmental sustainability. This paper aims to contribute to the literature by offering an analytical study of the mentioned E3 mainly to the developing countries.

The Analysis was based on a review of the literature and supported by theoretical models about energy, economy, and environment. Zanzibar is importing its energy source form Tanzania mainland through the supplier known as Tanzania Electric Supply Company Limited (TANESCO) which make it more dependent from one primary source of energy that poses many challenges in its socio-economic development. This paper can be used by policymakers while during their policy-making process regarding energy, economy, and environment. The paper has also presented the challenges of the environment in the rapidly growing economy. The author has analysed and discussed these challenges, and its success or failure can be used as a model in other developing countries. This study can help (potential) Government officers, policymakers, and regulators to assess policy risks between energy, economy, and environment.
\end{abstract}

Keywords: energy; economy; environment; Zanzibar Economy; policy risks; energy security; Energy Economy DOI: $10.7176 / \mathrm{JRDM} / 53-08$

Publication date:March $31^{\text {st }} 2019$

\subsection{Introduction}

Zanzibar consists of two islands of Unguja and Pemba. There are also some other small islands. The islands are located in the Indian Ocean about $40 \mathrm{~km}$ off the Mainland coast of Tanzania mainland.

Zanzibar Islands have a total area of 2,654 square kilometres. Unguja has an area of 1,666 square kilometres and Pemba has a land area of 988 square kilometres. The climate in Zanzibar is tropical and humid with an average maximum temperature of about 30c degree recorded during hot seasons and an average minimum temperature of $21 \mathrm{c}$ degree recorded during the cold season.

From the graph 1, We see that The Population of Zanzibar in 2018 is estimated to be 1.57 million.

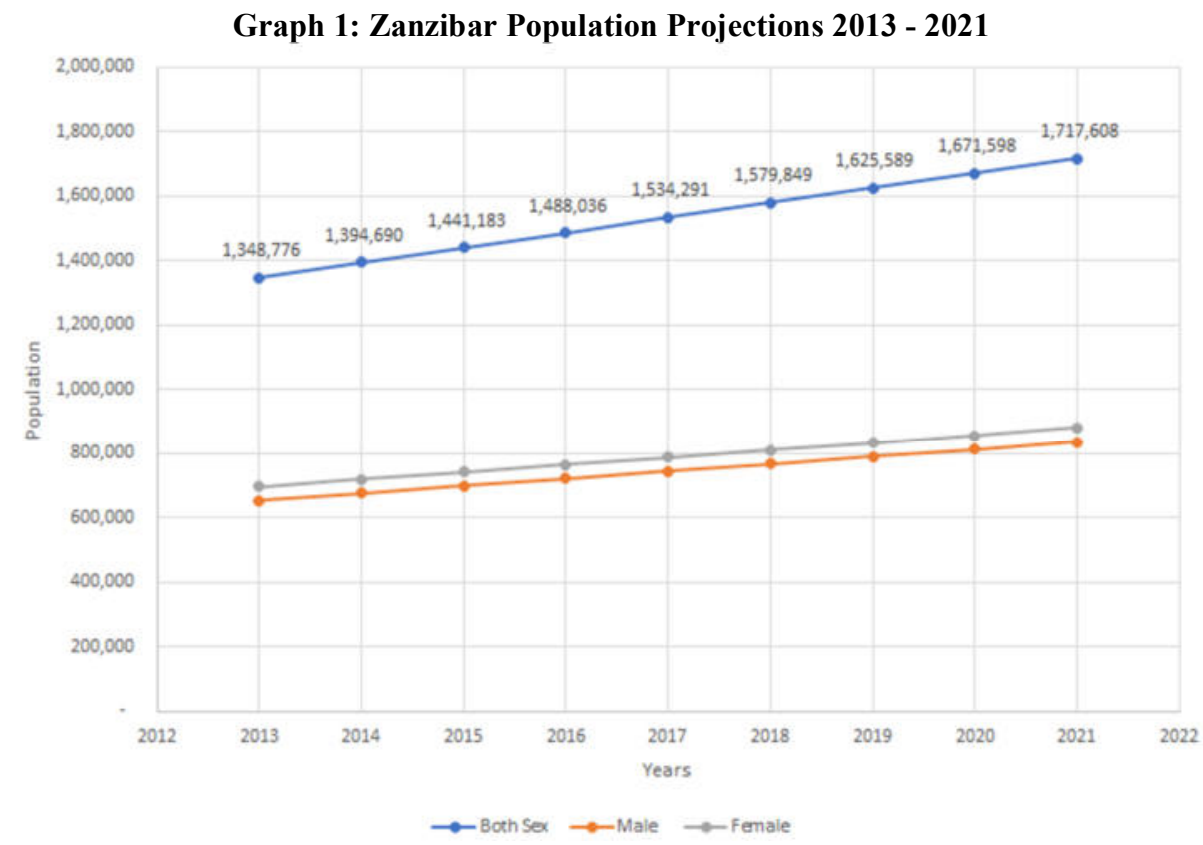

Source: Office of the Chief Government Statistician Zanzibar (OCGS Zanzibar). 
The sustainable development of any developing country like Zanzibar is mainly focusing on the goal of attaining higher standards of living of its citizens (including goals like high educational, good health and infrastructure). To attain these goals some key sector namely Energy, Economy, and Environment need higher attention. Zanzibar is a dilemma in balancing the three, i.e., Energy, Economy, and Environment.

\subsection{An Overview of World Energy}

Global economic growth strengthened in 2017 with reported growth of $+3.7 \%$ that were in line with its 2000-2015 average (EnerData 2018) that also resulted into acceleration in energy consumption by $2 \%$ on average.

The highest energy consumer in 2017 was China with $28 \%$ world energy consumption total share followed by the USA which consumed $20 \%$ of world energy.

Figure 1: Crude oil prices 1861-2017 US dollars per barrel, world events

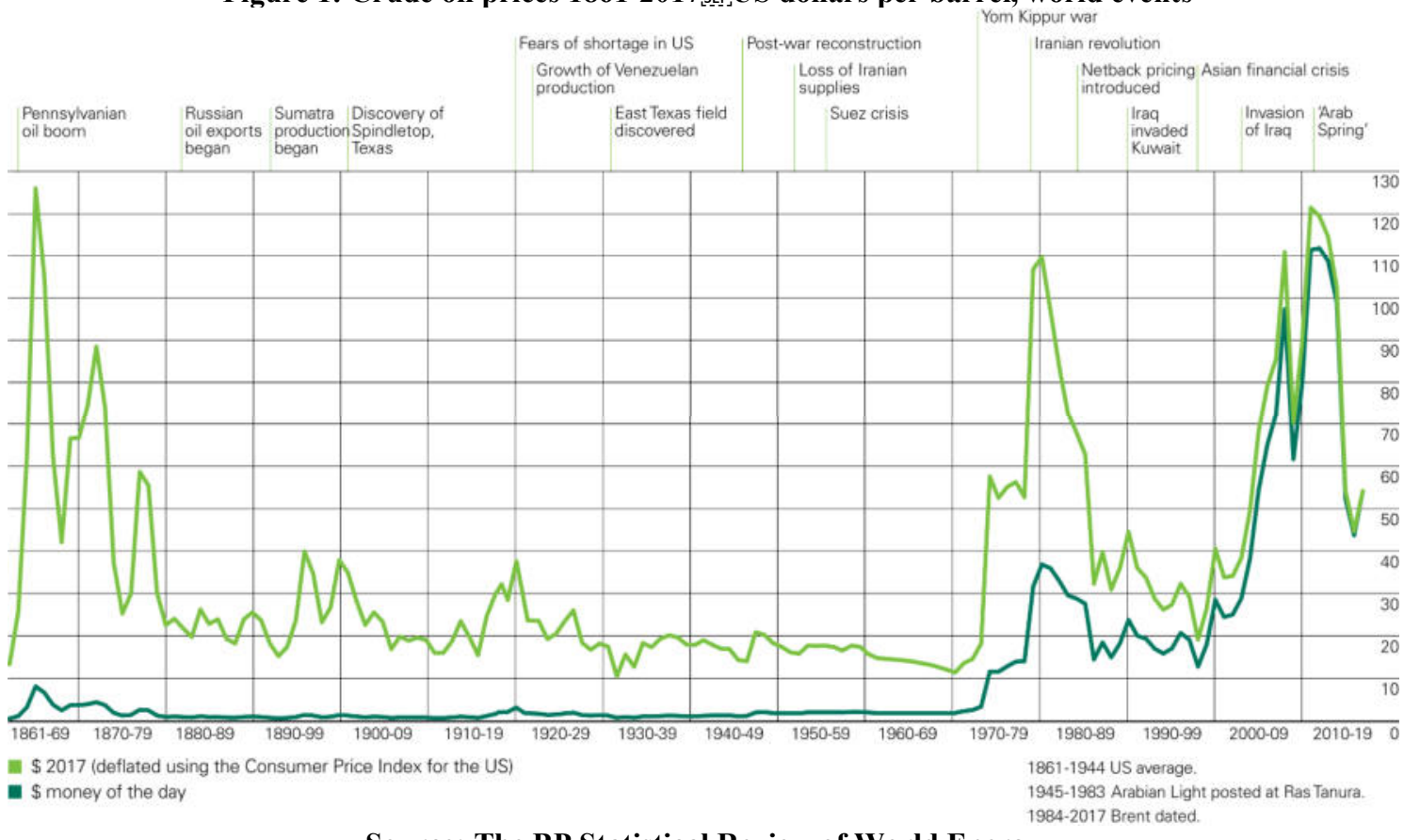

Source: The BP Statistical Review of World Energy

The crude oil prices during 2010 - 2019 was very volatile, and this was mainly contributed by several world events including Iraq war, Arab uprising and the Asian financial crisis (See figure 1). Energy production is still highly dependent on the supply of oil and if there is volatility of oil prices in the world causes social unrest and a business slowdown in some part of the world.

This is to say; world politics has a direct influence on energy sector especially from OEC countries. The recent example of Qatar and Saudi Arabia diplomatic stand own raised a fear on energy security to Saudi Arabia as it is well known that Qatar is the principal supplier of oil and gas to her neighbour, Saudi Arabia. 
Figure 2: G20 KEY Energy Figures in 2017

\begin{tabular}{|c|c|c|}
\hline مी & $(\sqrt[3]{)}+2.1 \%$ & $\mathrm{CO}_{2}$ \\
\hline $\begin{array}{l}\text { Economic growth } \\
\text { At purchasing power parity }\end{array}$ & $\begin{array}{l}11.1 \text { Gtoe } \\
\text { Rising energy } \\
\text { consumption }\end{array}$ & $\begin{array}{c}27 \mathrm{GtCO}_{2} \\
\text { Rebound in } \mathrm{CO}_{2} \\
\text { emissions* }\end{array}$ \\
\hline $\begin{array}{l}2016: \quad+3.1 \% \\
2005-15:+3.5 \%\end{array}$ & $\begin{array}{l}2016: \quad+1 \% \\
2005-15:+1.6 \%\end{array}$ & $\begin{array}{l}2016: \quad-0.5 \% \\
2005-15:+1.7 \%\end{array}$ \\
\hline
\end{tabular}

*: $\mathrm{CO}_{2}$-energy emissions from energy combustion ( $>80 \%$ of $\mathrm{CO}_{2}$ emissions)

\section{Source: World Energy Trends - 2018 Edition, Webinar - ENERDATA}

- $\mathrm{G} 20$ countries account for $80 \%$ of global energy consumption

- $\mathrm{CO}_{2}$ Energy emissions from energy combustion (>80\% of $\mathrm{CO}_{2}$ emissions)

From the figure 2 above shows that, while G20 had an average of 3.7\% economic growth in 2017 compared to $3.1 \%$ in 2016 but this resulted to rising consumption of energy by $2.1 \%$. These economic growths had also resulted into $2 \%$ increase of $\mathrm{CO}_{2}$ emissions in 2017.

According to the Paris COP21 Agreement, the countries who are signatories of the agreement declared to limit their growth in temperatures to $2^{0} \mathrm{C}$ and cut their energy-related $\mathrm{CO}_{2}$ emissions average $2.9 \%$ per year.

Although many G20 countries including China and the USA has signed the Paris COP21 Agreement but generally speaking the Global economy has not yet started to cut its $\mathrm{C}_{2}$ emissions.

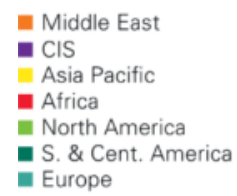

Figure 3: Distribution of proved gas reserves: 1997, 2007 and 2017
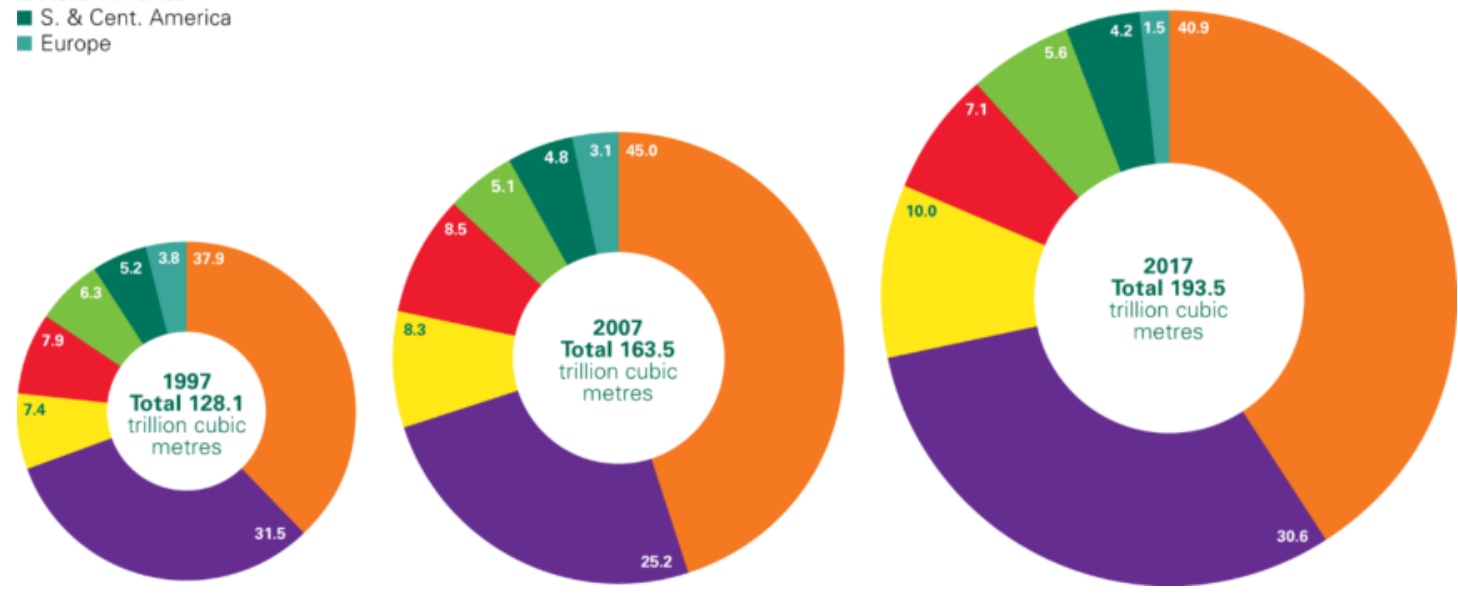

Source: The BP Statistical Review of World Energy

According to several reports, even though there was a substantial price increase on coal markets, but coal has remained the primary source of energy consumed in 2017 . For example, China uses $60 \%$ coal as the primary source of energy production. Figure 3 above, There are 193.5 trillion cubic metres of already proved reserve of gas worldwide. Middle East account for $40.1 \%$ of the total proved gas reserve in the world while Africa's recent gas discovery has made the continent to participate in energy economy with $7.1 \%$ of the proven gas reserve. 
Also, there is increasing trend for crude oil prices that was as a result of production cuts by the leading world oil producers, the significant impact of geopolitical events in early 2018 (Iran, Venezuela) and global economic growth.

Figure 4: 2018 World Energy Summary

(更)

\section{Increased energy consumption} for all markets, including coal

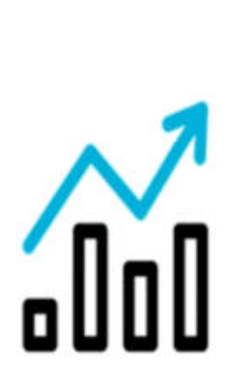

$$
\text { GAS }
$$

× Electricity

Rising electricity demand, faster than global energy demand

7 ort

Increase in oil demand above historical trends

COAL

Higher coal consumption after 3 years of decline, spurred by India and Turkey

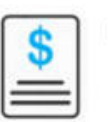

- Trend reversal with increasing oil and gas prices

- Significant increase in coal prices

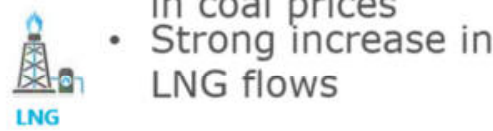

LNG

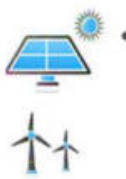

- Strong momentum for renewables

$+23 \%$ generation $52 \%$ of global power generation increase

\section{Source: World Energy Trends - 2018 Edition, Webinar - ENERDATA}

From these recent energy global trends, we can see that critical global players (G20) are on a mission to efficiently use available energy resources to support their economic growth while also in a mission to protect the environment, please see figure 4 .

\subsection{Literature Review}

The worldwide demand of energy has recently increased rapidly due to the noticeable growth of global population and economy, particularly in the emerging market economies. Possessing valuable energy supplies is always accompanied by development and prosperity, the rising demand for energy creates new challenges every day. Energy security threats may arise because more customers demand more energy resources ever, and higher fossil fuels consumption can lead to more greenhouse emissions, primarily carbon dioxide, which plays a huge role in global warming.

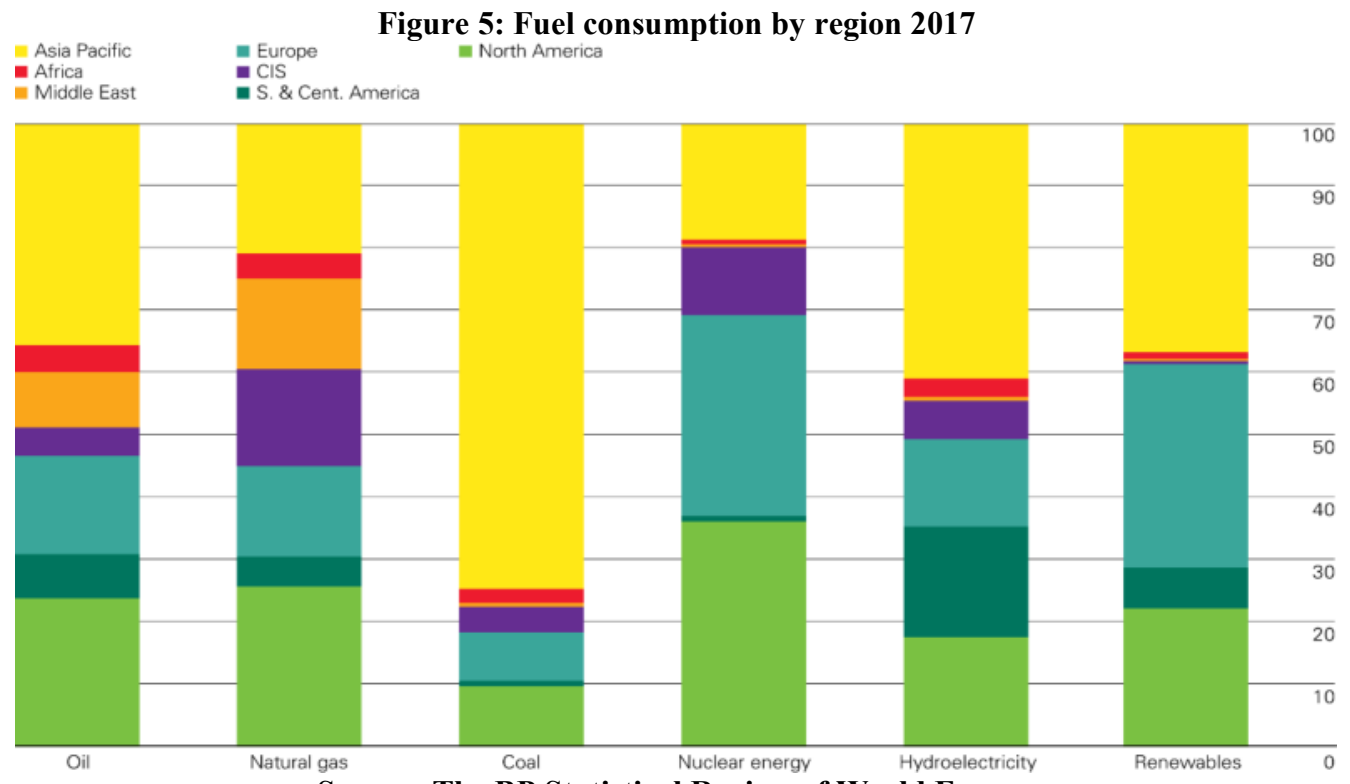

Source: The BP Statistical Review of World Energy 
The world fuel consumption is increasing due to regional economic growth. Some countries have implemented new energy policies of mixing sources of energy and become independent of traditional sources of energy which was oil, natural gas and coal. Figure 5 shows us for example, South and Central American countries have invested more on Nuclear energy. Asia Pacific countries have opted for hydroelectricity and renewables as their primary sources of energy.

However, from figure 5 we can also see Asia Pacific countries specifically China, are still very dependent on coal as their primary source of energy. Even though China is approving and installing new nuclear energy plants as a substitute for primary energy sources, but we can see that the road ahead is still very long.

Challenges that arise from such challenges can be a good source of opportunities. New thoughts, improvements and systems are required to sustain a sound energy future. We may need to change the way we produce, transport, store and consume our energy. If our primary target is to boost the living standards, afford new energy services, use energy more efficiently, protect our environment and surroundings, and assure the presence of energy resources, green growth is the solution.

The global energy production is at a turning point, from carbon-based fuels and nuclear power to renewables like wind or solar. This transition can only then be successful if large amounts of highly fluctuating renewable energy can be stored.

Today, electric supply must instantaneously match power consumption and new solutions for energy storage are in demand (Hydrogenious Technologies GmbH, 2018).

Figure 6: Renewable energy demand and storage

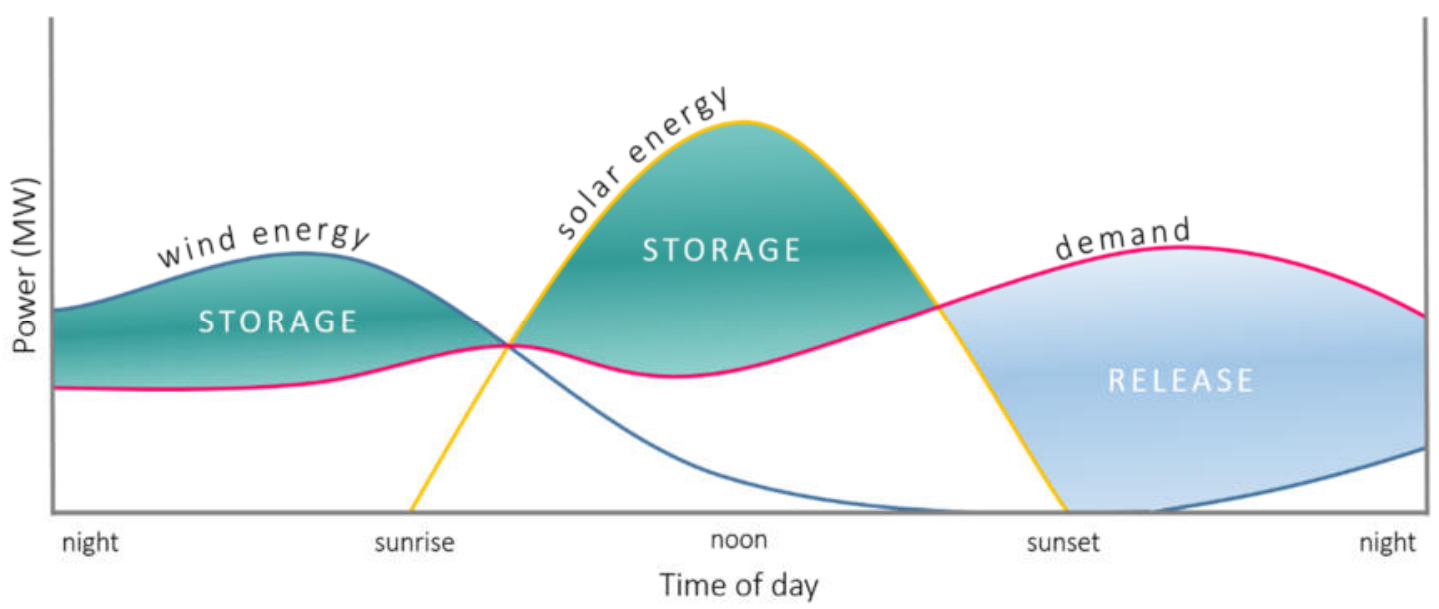

Source: Hydrogenious Technologies GmbH, 2018

Efficient energy storage allows to shift energy peak production from times of massive production to times of significant demand (see figure 6). Unsteady renewable energies in addition to that become base-load compatible and reduce the need for conventional base-load plants running on fossil fuels (Hydrogenious Technologies GmbH, 2018).

\section{History of the Energy system}

The power of muscles of human beings and in animals too was the first implementation of energy by human and the energy system in use was the food chain. Humans have always used energy systems to generate the maximum possible work with the minimum amount of effort to generate it. Before the industrial revolution, people mainly depended on muscle strength and biomass for their daily needs. Back in that time, biomass consisted mainly of wood and peat, and its energy delivery was not efficient.

Until the 19th century, the primary energy sources used were horse mills using Animal power, windmills using wind power and water wheel using water energy. Wood and charcoal were mainly used as fuels for cooking and heating purposes. However, coal and oil were available too. In the middle east, crude oils were recognised from seeps and leaks, but they were not mainly used as fuels, they were used as protective coatings (Smil, Vaclav. 1999) 


\section{What is Energy?}

Energy can be defined as the capacity to do particular work. Energy has a variety of forms, such as light, electricity, heat, motion, chemical, nuclear and gravitational. The sum of all energy forms possessed by a system is called total energy.

\section{Energy types}

Energy can be divided into two types which are primary and secondary. Primary energy is the energy obtained directly from the surrounding environment. Secondary energy is the energy transformed from Primary energy sources; it comes in the form of fuel or electricity.

Primary energy can be split into three different categories. The first category is the non-renewable energy like coal, natural gas and nuclear fuel. The second category is the renewable energy such as wind energy, geothermal energy, biomass and hydropower. The third category is the waste category.

Primary energy sources as crude oil, natural gas and coal contribute to about $85 \%$ of the total fossil fuels in the consumed primary energy in the world (DOE/EIA-0484) (Gary JH, Handwerk GH. 1994). Reports show that projected energy use in the world that until 2035 petroleum, coal and natural gas will still be the primary energy sources used by the world.

The principle of supply and demand suppose that as fossil fuels decrease, their prices will increase, and other energy supplies would be used instead. Renewable energy supplies such as biomass and wind energy will be economically suitable and affordable to use (DOE/EIA-0484) (Gary JH, Handwerk GH. 1994).

\section{Graph 2: Supply and Demand curves of RES}

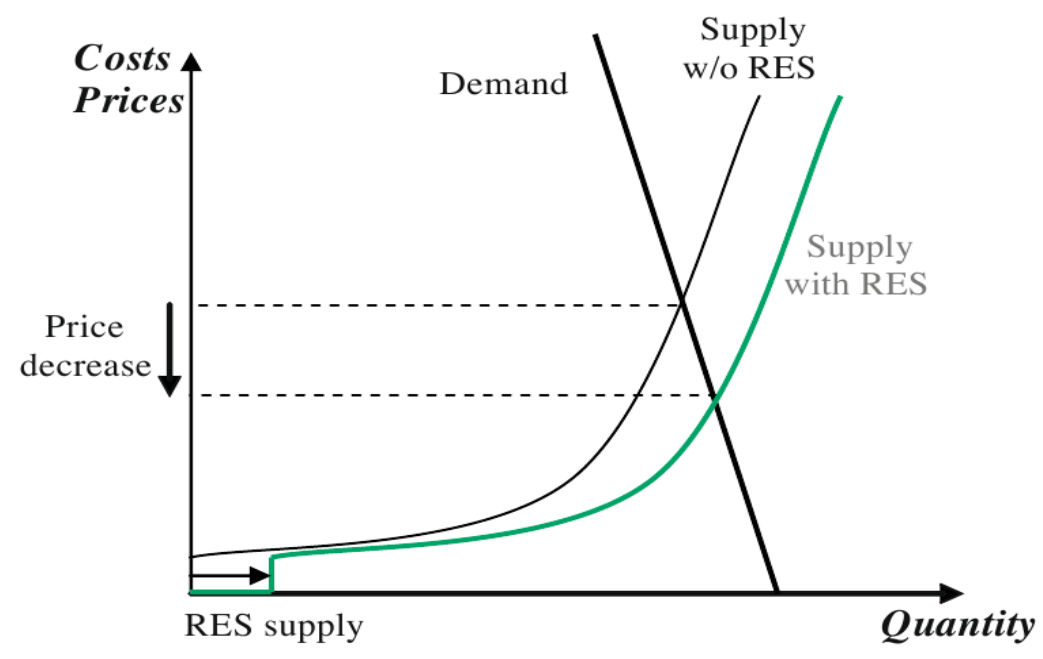

Indicative Supply \& Demand Cost structure (Weigt 2009)

As illustrated in graph 2, the supply and demand cost structure of renewable energy shows the price elasticity of renewable energy demand. The assumption is that, if the cost of renewable energy production is low the quantity supplied will be high and the vice versa is true.

The primary energy can be converted into secondary energy in the form of electricity or fuel, such as methanol, ethanol, hydrogen and gasoline (Belyaev, Marchenko, Filippov, Solomin, Stepanova, Kokorin 2002). The primary energy produced from renewable energy sources such as sun, biomass, wind or flowing water is usually equivalent to the electrical or thermal energy produced from them.

The final energy output is always electrical energy and fuel, and it is called useful energy. Electrical, thermal, mechanical and chemical energy forms place a boundary between energy consumption and production leaders (DOE/EIA-0484) (Gary JH, Handwerk GH. 1994). 


\section{The relationship between energy and the environment}

Energy generation and utilisation have a significant impact on the environment. The associated environmental problems with energy use include a spectrum of pollutant releases, hazards and accidents, as well as deterioration of environmental quality and natural ecology.

During the past few years, environmental threats related to energy have expanded from local issues to international and global threats. Especially in developing countries, where energy consumption rates are severely high, and the environmental management cannot yet fully afford such impacts.

Moreover, newly-industrialised countries are now the primary threat of air pollution, ozone depletion and carbon dioxide emissions due to the weak contribution of environmental management. In the 1970s, people mainly focused on the relationship between energy use and the economy, neglecting the impact of energy use on the environment.

In most countries, organisations were established to deal with environmental issues after 1970s many governments have set rules, environmental laws and management policies that were suggested to be the basis of government decisions concerning energy use and its environmental impact.

As environmental threats such as air pollution and ozone depletion became significant in the 1980s, more attention was given to the link between energy and the environment. Many studies were performed on energy and the environment. However, limited work was reported on that thread (Rosen M.A., Dincer 1996). The environmental impact of energy consumption is mainly decreased by raising the efficiency of energy-resource utilisation which is also called energy conservation.

Recently, the environmental impact of human processes and activities has dramatically increased due to the increases in the world population, energy consumption and developing industries. In the past, the majority of the environmental analysis and control authorities focused on the conventional pollutants such as Sulphur Oxide, Nitrogen Oxide and VOCs emitted by various material that have severely harmful effects on peoples' health. Recently, environmental attention has reached more hazardous air pollutants; they are mainly toxic substances that can harm people even in small doses. Such pollutants have various impacts on the biosphere (Hollander J.M., Brown 1992).

Carbon monoxide is a dangerous air pollutant. The incomplete combustion of vehicles fuels mostly generates it; it poses a great thread on human health. Sulphur Oxide is another harmful gas that is critical to human health and considered a threat to the surrounding environment; it is emitted globally due to natural phenomena such as erupting volcanoes or sea sprays and by human activities such as combustion of fuels containing Sulphur.

Nitrogen Oxides are generated due to combustions that take place in high temperature enough to start a reaction between Nitrogen and Oxygen. It can lead to breathing problems, defects in ozone formation and creating harmful acids that can be very dangerous to the natural systems. Nitrogen Oxide emission controlling is more difficult than controlling Sulphur Oxide because Sulphur Oxide emissions come from large public facilities such as power plants which can be easily recognised and controlled, While Nitrogen Oxides come from various sources such as motor vehicles which are smaller, mobile and present in large numbers.

VOCs and petroleum products disturb the natural formation of ozone. Various efforts are made to reduce VOCs emissions have conducted about $90 \%$ decrement in emissions of fuels that are not appropriately burned in the United States since the 1970s using catalytic converters (Hollander J.M., Brown 1992).

The global warming effect is another major problem that forms a critical thread to the whole globe. During the recent decades, the concern about the potential dangers due to the accumulation of greenhouse gases has been growing. The major problem is that such gases allow the absorption of infrared. Such gases give a chance for solar radiations from the sun to penetrate the Earth's surface, and at the same time, reabsorbing infrared radiations emitted from it. This problem is called the greenhouse effect or the global warming.

Global warming is considered the most critical energy-related environmental issue. The rising concentration of gases such as Carbon dioxide, halons, ozone and $\mathrm{CH} 4$ in the atmosphere, increases the atmosphere's capability to trap heat radiated from the Earth's surface, raising the overall temperature. Over the last century, the global temperature increased by about 0.6 Celsius degree, and therefore, the sea level was raised by about $20 \mathrm{~cm}$. Further impacts that have broad and catastrophic effects on human beings could have happened. 
Increasing in global concentrations of greenhouse gases along with predicted fossil fuel waste increment can cause the Earth's temperature to globally increase by 2 or 4 Celsius degrees, causing further increment in sea level by 30 to $60 \mathrm{~cm}$, which can lead to flooding of coastal cities, disturbance of vegetation, forcing people to leave their homeland and decreasing the amount of available fresh water.

Humankind is contributing through many of its economic and other activities to the increase in the atmospheric concentrations of various greenhouse gases. For example, $\mathrm{CO} 2$ emission due to combustion of fossil fuels, methane releases from increased human activity, $\mathrm{CFC}$ emissions, and deforestation all contribute to increasing the greenhouse effect.

Methods to effectively reduce the Carbon dioxide emissions needs analytical cost evaluation by governments. In the developing countries, the relationship between expenses and environmental benefits has to take into consideration the need for laws and policies that increase the economic growth. Fulfilling such a balance between emission control and economic growth requires adopting policies that aim at developing the efficiency of energy utilisation and implementing internal policies that allow easy access to new technologies and resources.

The arguments about the magnitude of the greenhouse effect have gone back and forth for some time. There are those who believe that the earth is doomed to a rise in temperature, and there are those who believe that we can go on polluting the atmosphere without consequence. Whatever the argument is, there is no doubt that the emissions are harmful and destroy the environment (Bradley, Watts, Williams 1991). Of course, there are several contradictory reports and arguments published recently that make this field complicated to study.

Moreover, more attention should be given to the environment considering it an insufficient resource, and chemical discharging should be subjected to strict constraints.

It is expected that some countries will offer specific tax reductions for those businesses that promote renewable energy technologies, mainly because of low or zero $\mathrm{CO} 2$ emission characterises these technologies.

\section{Energy and Economy:}

Energy fuels the economy. The importance of energy and its role in the economic growth initially comes from its importance in production. According to production theories, the economy is represented as a closed system where inputs are workforce and capital, and output is the product. Therefore, economic improvement results from improving inputs or raising their quality.

The critical role of energy in production is indirect, and it is considered as an intermediate input in the production system. According to Stern (Stern, D. 1991), there are primary and intermediate factors of production; the mainstream economists accepted such a concept.

Primary factors are the factors that are not directly used in the production process, and they must be available at the beginning of the process, while common factors are factors which are used in the process of production. Primary factors include labour, land and capital, while common factors include energy, materials and fuels. Georgescu-Roegen was the first to stress the critical role of energy in the prosperity of the economic system in 1971 (Georgescu-Roegen 1971).

After the oil crisis in the $70 \mathrm{~s}$ and $80 \mathrm{~s}$, much more attention was given to the energy resources and their price. Any increase in the energy price will result in an increase in the domestic price level and a reduction in the output in the short run. Such a situation reduces the general demand and may force industrial firms to change or to hold up their investment programs, mainly because higher energy prices may lead to the higher interest rate. The supply response of labour and capital to such a situation will determine the impact on output and employment. Increased energy prices lead to increased input prices which eventually lead to decreased profitability (Nela, Saša 2010).

Energy is an essential pre-requisite in the economic growth process. It is critical for the necessary transformation to a more sustainable world where we can all have access to energy services to a more comfortable and secure life.

In the same time, a healthy economy is required to assure that energy demands are available, that investment plans and infrastructure work are well carried out and that more research and development are taking place to ensure future prosperity. 
It is obvious nowadays that the leading countries worldwide are the countries with more energy resources. Owning a massive portion of the energy resources worldwide sometimes lead to controlling the global economy. Energy resource has been and will always be the target of every developing and already-developed countries.

Recently, much more attention was given to the renewable energy resources worldwide. Crude oil and natural gas are essential now, but they will not have such importance forever as they may run-out in any time. Therefore, the future of energy depends on the renewable sources such as wind, hydropower, biomass and solar energy.

Moreover, unlike petroleum products, renewable energy resources are environmentally friendly and nearly have no harmful impacts. More attention, investment and time should be given to developing the way we extract and use the renewable energy resources in the future because in all ways they are much better than the sources we are using now.

As we can notice, the impact of energy and economy on one another is mutual. In one hand, the Improved economy in certain societies makes it easier to afford enough energy demands. On the other hand, available energy resources can lead to the prosperity and economic growth of a particular society.

\subsection{Theoretical Frameworks}

\subsection{Porter hypothesis}

According to the Porter hypothesis, strict environmental regulations can induce efficiency and encourage innovations that help improve commercial competitiveness. The economist Michael Porter formulated the hypothesis in an article in 1995 (Wikipedia).

The hypothesis suggests that strict environmental regulation triggers the discovery and introduction of cleaner technologies and environmental improvements, the innovation effect, making production processes and products more efficient (Wagner, M 2003), Please see figure 7.

Figure 7: The Porter hypothesis

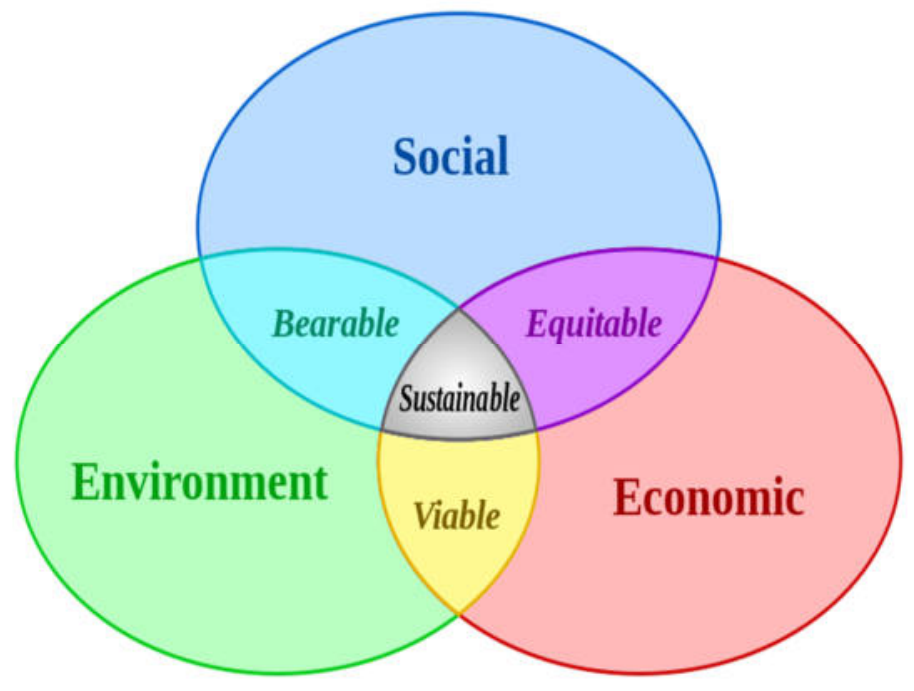

\subsection{E3 Model}

As the global climatic change is growing, many researchers have realised that there is a need to research on the relationship between energy, environment, and economics in different regions or at a country level.

E3 models is an integrated view on environment, energy, and economy. E3 models can quantify effects on the energy system, economy and environment simultaneously. Therefore, E3 models are usually no partial models, and they provide an integrated view of sustainability. Possible impacts of political measures can be evaluated, and rebound effects, winners, and losers can be identified (Anett 2014).

Well-known examples of E3 models are GEM-E3 from the European Commission (e.g., Kouvaritakis et al. 2005) and E3ME from Cambridge Econometrics (e.g., Pöyry, CE 2014). 
Figure 8: Model of the Study - Zanzibar Environment-Energy-Economy

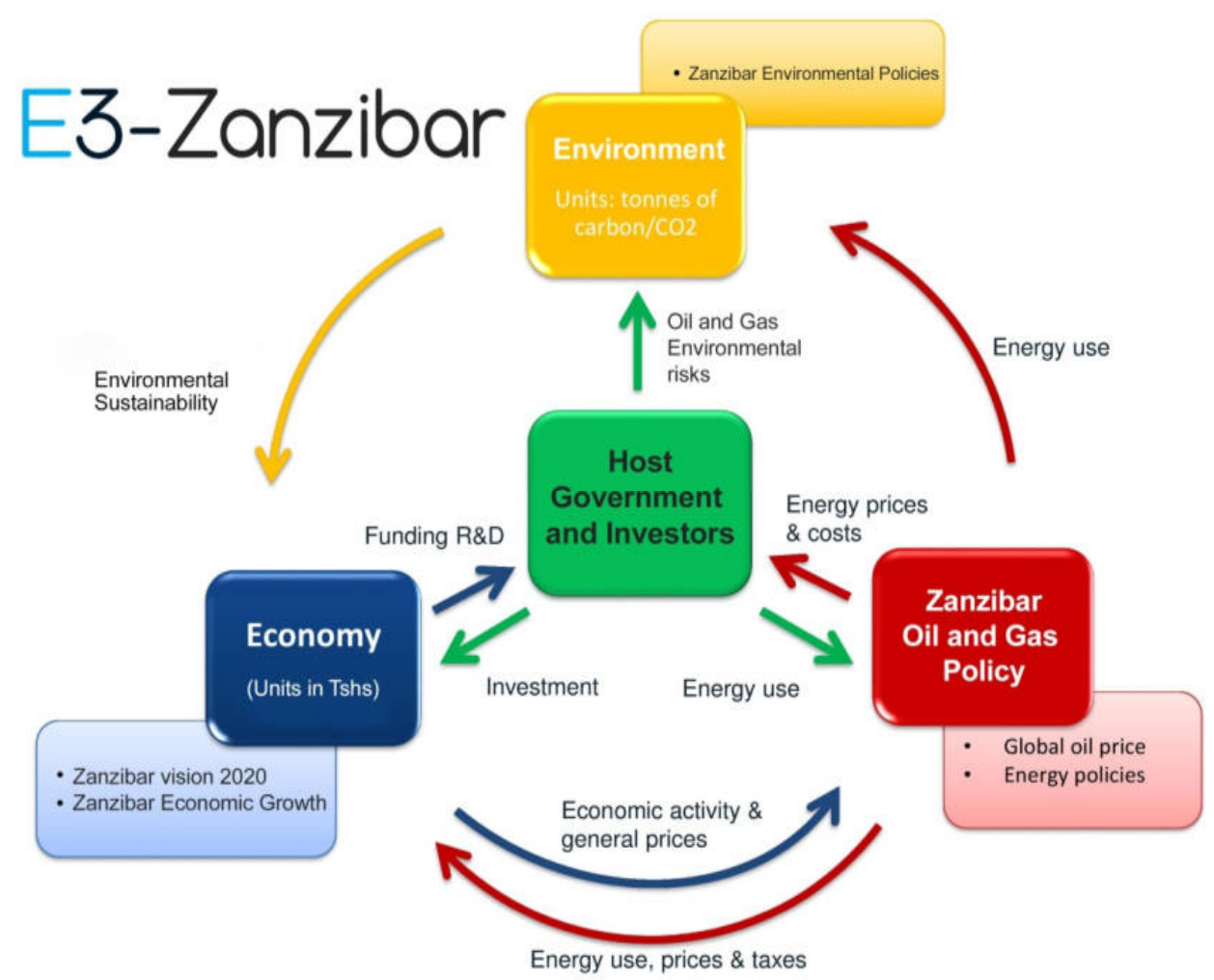

Adopted from The Regulatory Assistance Project: The E3-India Model

Theoretically, both the Porter hypothesis and E3 Model support this study. It has been proved that under the strict balance between Economy and Environment has a direct relationship whereby one can have a more significant impact on the other.

Zanzibar needs to apply these two models if it wants to sustain its long-term economic development while also safeguard its environment and hence use reliable environmental friendly energy sources, please see figure 8 .

\subsection{Zanzibar's Dilemmas in Energy, Economy, and Environment 4.1 Zanzibar Energy consumption}

Zanzibar Islands gets most of its electric power from mainland Tanzania through a 39-kilometre, 100-megawatt submarine cable from Ras Kiromoni (near Dar es Salaam) to Ras Fumba on Unguja and Pemba Islands has had a 75-kilometre, 25-megawatt, subsea electrical link directly to mainland Tanzania.

The laying of 75-kilometer, 25-megawatt new submarine cable, subsea electrical link project that was funded by a 28.1 Million USD grant from the United States of America through the Millennium Challenge Corporation that was implemented in 2012 (Embassy of the United States, Dar es Salaam, 2012). The cable became operational on 13 April 2013 (Daily News, 2013). The previous old 45-megawatt cable, which was not well maintained, was installed by Norway in 1980 .

This project ended years of another unreliable source of energy dependence during the frequent power cuts in Zanzibar. Before this project, it was estimated that only $20 \%$ percent of the old cable's capacity was being used, The new cable is expected to serve Zanzibar Electricity supply needs for about 20 - 25 coming years.

Because Zanzibar has not invested heavily in industries or manufacturing sectors, it is estimated that 70-75 of its electricity consumptions are mainly for households needs. The Zanzibar residents also rely on another source of energy including coal and wood. The consumption capacity of petroleum, gas, oil, kerosene and industrial diesel 
oil is increasing annually, going from a total of 5,650 tons consumed in 1997 to more than 7,500 tons in 1999 (Nexans 2013).

From 21 May to 19 June 2008, Unguja suffered a significant failure of its electricity system, which left the island without electrical service and mostly dependent on diesel generators. The failure originated in mainland Tanzania (BBC 2008).

\subsection{Zanzibar Economy}

The Zanzibar economy is mainly agriculture. There is vast fertile land that produces agricultural products enough for Zanzibar population which is estimated to be 1.5 million. Zanzibar mainly exports seaweed, spices, cassava, sweet potatoes, citrus fruit, coconuts, and cacao. Zanzibar is also importing products like rice, cigarettes, shoes, clothes and processed products. Zanzibar is mainly importing from China, India and other Asian countries.

Tourism is growing fast in Zanzibar that also supports its economy. About 50 percent of the Isle's population would be involved in tourism activities by the year 2020, forecasting a robust growth of the sector in few years to come. So far, tourism is a source of Zanzibar's foreign currency earnings by 70 percent. (The Revolutionary Government of Zanzibar).

According to (UN Data 2018) Per capita GDP, US dollars of Zanzibar increased from 201 USD in 1990 to 823 USD in 2016 growing at an average annual rate of $3.96 \%$.

Graph 3: The per capita GDP of Zanzibar

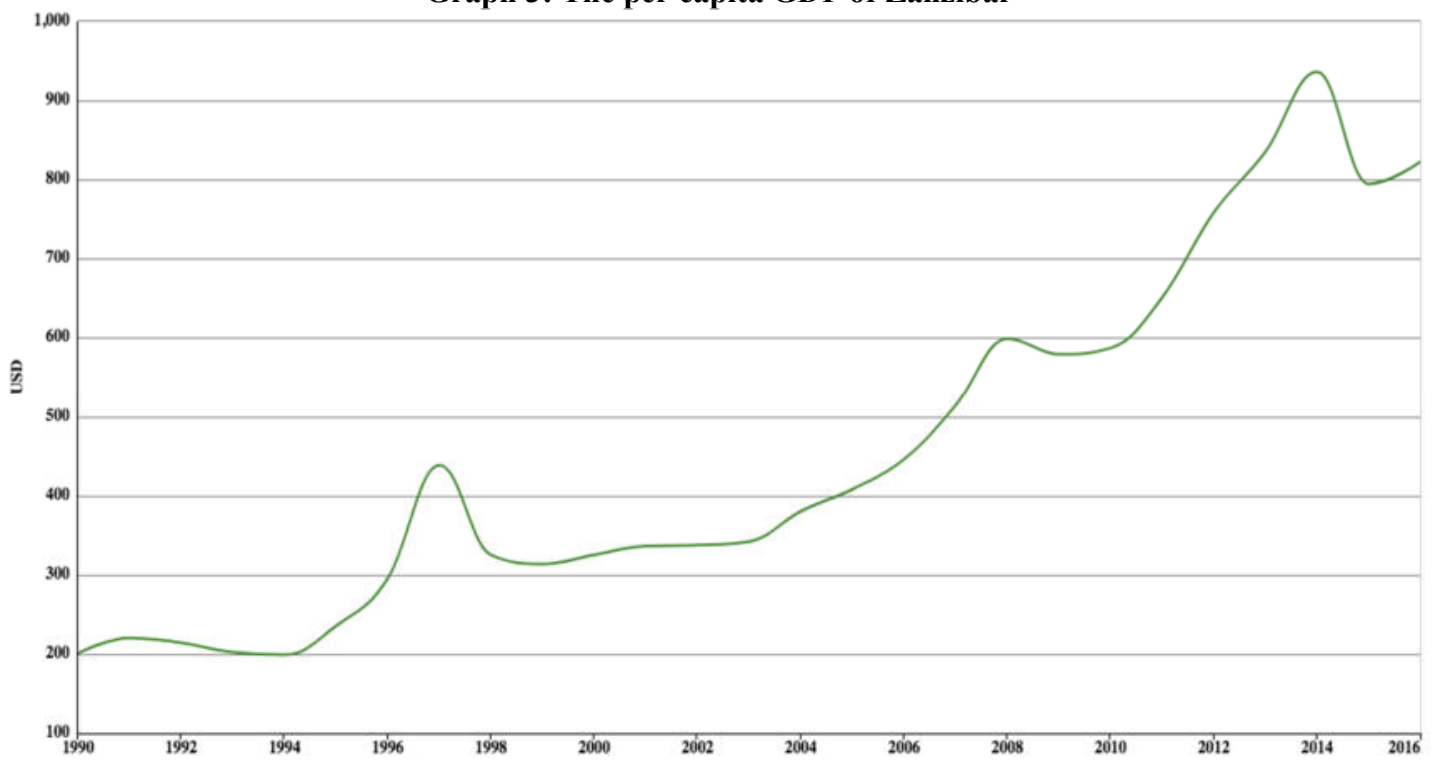

Source UN Data (National Accounts Main Aggregates Database)

Zanzibar economy has been stable for years. The GDP growth increases from 6.6 percent in 2015 to 6.8 percent in 2016, (Please see graph 3). Similarly, per capita income increased from US\$ 817 in 2015 to 830 in 2016. Zanzibar Annual Headline Inflation rate for the year ended June 2018 increased to 3.5 percent compared to 2.7 percent recorded during the year ended May 2018. (OCGS Zanzibar).

\subsection{Zanzibar vision 2020}

Zanzibar government has worked hard to improve the Isles' economy and changing the socio-economic status of its citizens. The Revolutionary government of Zanzibar, to solve socioeconomic issues, in 2000 comes up with new Policy namely, Zanzibar Vision 2020 which aimed at promoting Zanzibar economic growth while also eradicating poverty in the Isles. 
The overall Vision 2020's objective is to eradicate absolute poverty in the society. This is so because poverty is the single greatest burden for the people. Indeed, it is not merely the lack of income that determines poverty; it is also the lack of accessibility to the basic needs of the people (Zanzibar Vision 2020).

Since its establishment, The Revolutionary Government of Zanzibar has used this policy to come up with strategies of supporting its economic growth.

Ten years after the dawn of the millennium, significant changes have swept both the world and Zanzibar. While developed countries suffered from the global financial crisis, many developing countries are catching up. As well as steady progress and poverty reduction in China and India, there has been unprecedented economic growth in Sub-Saharan Africa (Zanzibar Vision 2020).

To achieve the Zanzibar vision 2020, There were critical issues to be addressed including Energy and Environment. Zanzibar Islands are too dependent on energy import from the neighbouring Tanzania mainland. Some of the economic development goals were not achieved due to lack of enough supply of electricity to supports the Tourism sectors and other vital industries.

"We should make a smart, with selective and strategic investments in human resources, high-quality health care, and basic and advanced infrastructure for transportation, electricity, water, and communication. We need to make more concerted efforts to conserve the natural environment" (Dr Ali Shein 2011, President of Zanzibar).

To achieve this socioeconomic growth, Zanzibar needed well-planned energy policy long-term strategies which were lacking. To cite an example, in 2008, Zanzibar suffered a four-week blackout. This month-long power blackout did threaten the tourism sector which is the primary source of foreign currency income.

The power cut was caused by a submarine cable that was broken and necessitated the needs to be replaced with the new cable as it was not capable of supplying the quantity of energy demanded in Zanzibar.

The author believes that, if there were a balance between Energy and Economy in the Zanzibar Vision 2020 Policy, the policy could have resulted in more socioeconomic solutions.

\subsection{Zanzibar Environment Concerns}

Recognizing the importance of its environment, the Revolutionary Government of Zanzibar launched the National Environmental Policy for Zanzibar in 1992.

The policy was deliberately launched to provide policy guidance intending to protect and improve the environment in a manner which contributes to the quality of life of both present and future generations. (Zanzibar Environmental Policy, 2013)

The Paris Agreement was adopted on 12 December 2015 at the twenty-first session of the Conference of the Parties to the United Nations Framework Convention on Climate Change held in Paris from 30 November to 13 December 2015 .

Under its article 20, the Agreement shall be open for signature at the United Nations Headquarters in New York from 22 April 2016 until 21 April 2017 by States and regional economic integration organisations that are Parties to the United Nations Framework Convention on Climate Change (United Nations 2018).

On 22nd April 2016, The United Republic of Tanzania signed the COP21 Paris Climate Change Agreement. Tanzania Mainland also represents Zanzibar as their signatory on the issues that need foreign representations. The reports show that climate change is already having a profound impact on the lives of millions of Africans (Including Zanzibaris) and it also has impacted the economic development of the African countries.

In recent years, there has been renewed optimism on the prospect of harnessing Africa's natural resources to realise social, economic and political transformation and deliver sustainable development and prosperity to citizens (Climate Strategies, 2016).

Even though many African countries including Tanzania (Zanzibar) has signed the Paris Agreement, but it is very questionable if these developing countries can well deliver its pledges. Many of the developing countries lack the technological development and climate change funding, and it is the role of developed countries to support these initiatives. 
At the national level, still, Zanzibar need to address its climate and environmental challenges associated with its economic development, but also come together to press harder for their interests on an international level. It is believed through the geopolitical union with Tanzania mainland and also the new revived East African community, Zanzibar can get the needed support to address the said challenges.

\subsection{Sustainability Considerations}

From this study, the author has found that The E3 dilemma, in the short term, gives an understanding on how to tackle the challenges of balancing the rapid economic growth with environmental challenges associated with it. The study has also highlighted the problems of not having the long-term strategies of supporting the economic growth with its expected environmental challenges. Even though Zanzibar has national economic strategy namely, Zanzibar vision 2020, but the author has found out that, there are no clear strategies to tackle the environmental problems that are brought with economic growth.

The supply of national grid electricity from Tanzania Electric Supply Company Limited (TANESCO) as the only primary source of energy in Zanzibar is always insufficient to meet local energy demand. Politically, always relying on the import of energy resources is also another challenge to be addressed.

The author believes that, Because of its geolocation and its proximity to India ocean, it is the right time now for Zanzibar to consider using other sources of renewable energy including solar and wind sources. Through Publicprivate partnership (PPP) funding model, the Zanzibar Government has an opportunity to invite international investors to fund the renewable energy projects in Zanzibar.

It has always been reported that the high rise in energy demand is also bringing up the prices of energy sources. This poses yet another political and socioeconomic challenges as many citizens will not afford the prices of energy sources for their daily use.

To balance between Environment and Energy, the decision makers should always focus on renewable energy sources while deciding the next energy projects. Zanzibar can decide whether to invest in large-scale wind or solar energy project to complement the demand of energy in the Islands. The Zanzibar government has previously invested in Industrial scale diesel generators, but because of the high prices of diesel in Zanzibar and the cost of running the project, the operation of this project was halted and discontinued.

Even though the initial investments of renewable energy sources are higher than the natural sources, But the author has proposed Public-private partnership (PPP) funding investment model which has better economic benefits in the long run. To make Zanzibar environmental friendly energy country, we should consider an E3 model that creates a need balance between energy, economy, and environment.

\subsection{Conclusion}

Zanzibar vision 2020 has always promoted economic growth, promote tourism as the critical sector for foreign currency income and supporting the agriculture as the national economic backbone, but it is worth to mention that, all these economic growths need high energy use and will bring environmental cost. In this paper, the author has discussed the Zanzibar E3 Dilemma and proposed possible solutions. The author also believes that to solve this dilemma in the long run, Zanzibar still needs to revise its long-term Energy, Economy, and Environment Policies.

Strategically, Zanzibar needs to find solutions if they do not want to become energy dependent in the long run while also ensuring the sustainable economic developments. This also can help to safeguard its national interests by ensuring there is always energy security in the Islands. Zanzibar must also adhere to international environmental agreements including the Paris COP21 Environment Agreement. This relationship between energy, economy, and environment has a direct impact on social, economic issues in the sovereign country like Zanzibar.

\section{Conflicts of Interest}

The authors declare no conflict of interest.

\section{The Data Availability Statement}

The data used to support the findings of this study are available from the corresponding author upon request 


\subsection{References}

1. Anett, Grobmann (2014) Forecasting the 3E's (Environment-Energy-Economy): The Austrian model e3.at, Institute of Economic Structure Research (Gesellschaft für Wirtschaftliche Strukturforschung $\mathrm{mbH}$ ), Osnabrueck, Germany

2. $\quad$ "Ambassador Lenhardt Participates in Ceremony to Install 100 Megawatt Submarine Power to Zanzibar". Press Release, Embassy of the United States, Dar es Salaam, Tanzania, 10 October 2012.

3. Belyaev LS, Marchenko OV, Filippov SP, Solomin SV, Stepanova TB, Kokorin AL .World energy and transition to sustainable development. Kluwer, Boston. 2002

4. Bradley R.A., Watts E.C., Williams E.R. Limiting Net Greenhouse Gas Emissions in the United States. U.S. Department of Energy, Washington, DC. 1991.

5. DOE/EIA International energy outlook. Report \#:DOE/EIA-0484. 2010. http://www.eia. gov/oiaf/ieo/highlights.html

6. Energy in 2017: Two steps forward, one step back, Spencer Dale London 13 June 2018

7. Forecasting the 3E's (Environment-Energy-Economy): The Austrian model e3.at: Anett, Grobmann, Institute of Economic Structure Research (Gesellschaft für Wirtschaftliche Strukturforschung mbH), Osnabrueck, Germany

8. Gary JH, Handwerk GH. Petroleum refining technology, 3rd edn. Marcel Dekker, New York. 1994.

9. Georgescu-Roegen, N. The Entropy Law and the Economic Process, Harvard University Press, Cambridge, Mass. 1971.

10. Hollander J.M., Brown D.Air pollution. In: The Energy-Environment Connection, J.M. Hollander, ed., Island Press, Washington, DC, pp. 15-49. 1992.

11. Illustration 25: Indicative Supply \& Demand Cost structure for Energy Showing demand Price inelasticity (Weigt 2009)

12. List of parties to the Paris Agreement - Wikipedia.

https://en.wikipedia.org/wiki/List_of_parties_to_the_Paris_Agreement

13. Nela Vlahinić-Dizdarević, Saša Žiković. The role of energy in economic growth: the case of Croatia. 40 Zb. rad. Ekon. fak. Rij. vol. 28. sv. 1. 35-60. 2010

14. Paris Agreement in practice: what next for Africa and developing countries? Claudia Delpero - Climate Strategies (2016), Based on the proceedings of the 3rd Global Climate Policy Conference Dar es Salaam, Tanzania, 13-14 July 2016

15. Pascal, Charriau, and Crenes, Morgan (2018) - Global Energy Trends, A step backwards for the energy transition? Based on its 2017 data of G20 countries, EnerData analyses the World energy markets trends.

16. Press release (3 June 2010). "Nexans Completes Subsea Cable Link to Provide Reliable Power for Pemba Island in Zanzibar - New 25 MVA Link to Mainland Grid Has Enabled the Local Population to End Years of Dependence on Unreliable Diesel Generators". Nexans. Retrieved 14 September 2013.

17. Porter hypothesis - Wikipedia. https://en.wikipedia.org/wiki/Porter_hypothesis

18. Rosen M.A., Dincer I. Linkages between energy and environment concepts, Proceedings of the TIEES96 First Trabzon International Energy and Environment Symposium (T. Ayhan, I. Dincer, H. Olgun, S. Dost and B. Cuhadaroglu, eds.), pp. 1051-1057, 29-31 July, Karadeniz Technical University, Trabzon, Turkey. 1996.

19. Smil, Vaclav. Energies: An Illustrated Guide to the Biosphere and Civilization. The MIT Press: Cambridge, MA, 1999. 
20. Staff (30 May 2008). "Melting in Zanzibar's Blackout." BBC News. Retrieved 14 September 2013.

21. Statistical Review of World Energy 2017, BP Plc, 1 St James's Square London, SW1Y 4PD, UK

22. Stern, D. I. "Is energy cost and accurate indicator of natural resource quality?", Ecological Economics, 31, pp.381-394. 1999.

23. The Breakthrough of Global Energy storage, Rethinking the way we store energy 2018. Hydrogenious Technologies GmbH - Germany accessed at http://www.hydrogenious.net/en/energy-storage/

24. The Regulatory Assistance Project (2017) The E3-India Model Technical model manual, Volume 5, Cambridge Econometrics, Cambridge UK.

25. The Economic Statistics Branch of the United Nations Statistics Division (UNSD) - 2018, Per capita GDP at current prices - US dollars. National Accounts Estimates of Main Aggregates

26. Tourism in Zanzibar - Revolutionary Government of Zanzibar. http://zanzibar.go.tz/index.php?rgo=tourism

27. United Nations (2018), Paris Agreement, Environment Chapter XXVII, Paris 12 December 2015 accessed at https://treaties.un.org/Pages/ViewDetails.aspx?src=TREATY\&mtdsg_no=XXVII-7$\underline{\mathrm{d} \& \text { chapter }=27 \& \text { clang }=\text { en }}$

28. Wagner, M.: The Porter Hypothesis Revisited. A Literature Review of Theoretical Model and Empirical Test. Lüneburg: Centre for Sustainability Management, 2003, p.2 CSM Lüneburg

29. Yussuf, Issa (24 April 2013). "Tanzania: Reliable Power to Accelerate Development in Isles President Ali." Daily News (via www.allafrica.com ). Retrieved 14 September 2013.

30. Zanzibar Environmental Policy (2013), The Revolutionary Government of Zanzibar, The First Vice President's Office - Department of Environment, Zanzibar.

31. Zanzibar Vision 2020, Development Partners Group (DPG) accessed at http://www.tzdpg.or.tz/fileadmin/_migrated/content_uploads/Zanzibar_Vision_2020.pdf

32. Zanzibar - Wikipedia. https://en.wikipedia.org/wiki/Zanzibar

33. Zanzibar Annual statistics Reports, 2018. Office of the Chief Government Statistician Zanzibar (OCGS Zanzibar), Zanzibar Tanzania. 